\title{
Quantification and Identification of Visible and Subvisible Particulates from Elastomeric Components Contributing to the Total Particle Count of Pharmaceutical Products
}

\author{
Evita McPherson ${ }^{1}$, Christopher Bingham ${ }^{1}$, Danequa Carter ${ }^{1}$, William Toomey ${ }^{1}$, Megan Scofield ${ }^{1}$ and \\ Rebecca Pulvirenti ${ }^{1}$ \\ 1. Luitpold Pharmaceuticals, QC Particulate Laboratory, Shirley NY, United States.
}

To perform a particle load evaluation on Ready to Sterilize elastomeric closures to better understand their potential contribution of particulate matter to finished product dosage forms, and at the same time perform representative particle identifications for investigational purposes. This study will compare retained particles evaluated at 40X (ISO) and 100X (USP <788>) and will include an assessment of particle load in the $\geq 10 \mu \mathrm{m}-\leq 25 \mu \mathrm{m}$ size range.

ISO 8871-3 Elastomeric parts for parenteral products and for devices for pharmaceutical use, provides a method for the determination of the number of visible and subvisible particle counts generated from surface washing of the elastomeric components [2]. However, ISO 8871-3 (i) does not specify any limits for particles generated by elastomeric parts, (ii) recommends that the evaluation be performed at a magnification 'of about 50X', and (iii) does not require the evaluation of particles that are in the $\geq 10$ $\mu \mathrm{m}-\leq 25 \mu \mathrm{m}$ size range [2]. This ultimately leaves it to the discretion of each elastomeric closure manufacturer to determine their own particle count limits, and subsequently the end user to determine acceptability of these reported results.

USP < 788> Particulate Matter in Injections provides the pharmaceutical industry with guidance on the quantification of particulate matter in injectable finished dosage forms [1]. The chapter requires injectable manufacturers to report particle counts in the $\geq 10 \mu \mathrm{m}-<25 \mu \mathrm{m}$ and $\geq 25 \mu \mathrm{m}$ size ranges from finished products [1]. Conversely, the elastomeric closure industry lacks any information pertaining to particle counts $\geq 10 \mu \mathrm{m}-\leq 25 \mu \mathrm{m}$ generated from their stopper products. This missing size range extends to data collected for their environmental blanks, and is possibly due to the 'of about $50 X$ ' magnification standard requirement set forth in the ISO guidance that can ultimately cause particulates in the $\geq 10 \mu \mathrm{m}-\leq 25 \mu \mathrm{m}$ size range to remain unseen [2]. Typically, the resolution of particles at $50 \mathrm{X}$ is about $20 \mu \mathrm{m}$ and greater. This unevaluated size range can have a significant impact on the pharmaceutical industry, considering that particle release limits per USP < 788> Method II, are no more than 3000 particles per container $\geq 10 \mu \mathrm{m}$ and no more than 300 particles per container $\geq 25 \mu \mathrm{m}$ [1]. Therefore, this study serves to investigate the particle counts on incoming Ready to Sterilize elastomeric parts (i.e. stoppers) using one of the USP particle size ranges $(\geq 10 \mu \mathrm{m}-<25 \mu \mathrm{m})$ in addition to the size ranges set forth in ISO 8871-3 $>25 \mu \mathrm{m}-\leq 50 \mu \mathrm{m},>50 \mu \mathrm{m}-\leq 100 \mu \mathrm{m}$, and $>100$ $\mu \mathrm{m})$ [1] [2]. Additionally, results at a magnification of $100 \mathrm{X}$ will be compared to results achieved at a lower magnification as advised in the ISO standard 'of about 50X' [2].

An in-house method has been developed to accurately assess the release of particles from elastomeric parts, and preliminary results on incoming stoppers have determined that the $\geq 10 \mu \mathrm{m}$ but $\leq 25 \mu \mathrm{m}$ size range has a significant impact upon the total particle counts. A more in-depth study of not only the particle load but also the specific particle types introduced by elastomeric parts could be of great interest to both the pharmaceutical and elastomeric industry, and a re-evaluation of the ISO standard considering 
the current industry focus on particles may be in order.

The method employed to release particles from the surface of the stoppers followed ISO 8871-3 "Elastomeric Parts for Parenterals and for Devices for Pharmaceutical Use - Part 3: Determination of Released-Particle Count", with minor modifications [2]. These modifications included the use of hand swirling the flask rather than mechanical rotating as well as counting the membrane at 100X magnification in addition to $40 \mathrm{X}$ magnification (fulfilling the 'of about $50 \mathrm{X}$ ' requirement). As per ISO $8871-3$, approximately $100 \mathrm{~cm}^{2}$ of stopper surface area were evaluated on each membrane [2]. The 13 $\mathrm{mm}$ stoppers investigated were manufactured with a fluoropolymer film and a cross-linkable polydimethylsiloxane. The total surface area of each stopper was $3.603 \mathrm{~cm}^{2}$.

Table 1 compares particle counts for $100 \mathrm{~cm}^{2}$ of stopper surface area at $40 \mathrm{X}$ magnification, which is in accordance with the ISO requirement 'of about 50X' [2]. A 100X magnification has been employed to investigate the particle load at a relevant magnification for the Pharmaceutical Industry (USP $<788>$ ) as stated above. It should be noted that a significant difference can be seen in the number of particulates $\geq$ $10 \mu \mathrm{m}-\leq 25 \mu \mathrm{m}$ counted at $40 \mathrm{X}$ versus that at $100 \mathrm{X}$ magnification. A smaller difference was observed in the $>25 \mu \mathrm{m}-\leq 50 \mu \mathrm{m}$ category. USP $<788>$ requires the finished product report of particles $\geq 10 \mu \mathrm{m}$ - $<25 \mu \mathrm{m}$ and $\geq 25 \mu \mathrm{m}$ [1]. The elastomeric closure industry, however, does not evaluate particles counts for the $\geq 10 \mu \mathrm{m}-\leq 25 \mu \mathrm{m}$ category. This missing information can have a significant impact on pharmaceutical manufacturing.

Although this study is still underway, particle types found on the membrane include light and dark particles, polymeric transparent particles, and translucent light particles. In general, the particles with sizes above $100 \mu \mathrm{m}$ were mainly light translucent particles, with a few fiber-like particles [3].

\begin{tabular}{|c|c|c|c|c|c|c|c|c|}
\hline & \multicolumn{4}{|c|}{ 40X Magnification } & \multicolumn{4}{|c|}{ 100X Magnification } \\
\hline & $\begin{array}{l}\geq 10 \mu \mathrm{m} \text { to } \\
\leq 25 \mu \mathrm{m}\end{array}$ & $\begin{array}{c}>25 \mu \mathrm{m} \\
\text { to } \\
\leq 50 \mu \mathrm{m}\end{array}$ & $\begin{array}{c}>50 \mu \mathrm{m} \\
\text { to } \\
\leq 100 \mu \mathrm{m}\end{array}$ & $>100 \mu \mathrm{m}$ & $\begin{array}{l}\geq 10 \mu \mathrm{m} \text { to } \\
\leq 25 \mu \mathrm{m}\end{array}$ & $\begin{array}{c}>25 \mu \mathrm{m} \\
\text { to } \\
\leq 50 \mu \mathrm{m}\end{array}$ & $\begin{array}{l}>50 \mu \mathrm{m} \text { to } \\
\leq 100 \mu \mathrm{m}\end{array}$ & $>100 \mu \mathrm{m}$ \\
\hline Membrane 1 & 97 & 5 & 1 & 2 & 381 & 91 & 10 & 3 \\
\hline Membrane 2 & 319 & 15 & 4 & 2 & 899 & 105 & 8 & 0 \\
\hline Membrane 3 & 144 & 21 & 1 & 1 & 487 & 118 & 19 & 6 \\
\hline Membrane 4 & 138 & 37 & 1 & 0 & 277 & 72 & 1 & 0 \\
\hline Membrane 5 & 76 & 22 & 3 & 3 & 325 & 77 & 11 & 3 \\
\hline Membrane 6 & 251 & 9 & 0 & 2 & 667 & 138 & 3 & 2 \\
\hline Membrane 7 & 509 & 18 & 0 & 0 & 1072 & 54 & 4 & 0 \\
\hline Membrane 8 & 585 & 11 & 3 & 2 & 1056 & 30 & 3 & 2 \\
\hline Membrane 9 & 449 & 8 & 2 & 1 & 900 & 25 & 3 & 1 \\
\hline $\begin{array}{l}\text { Membrane } \\
10\end{array}$ & 461 & 2 & 5 & 1 & 1092 & 8 & 5 & 1 \\
\hline
\end{tabular}

Table 1. Particulate counts (per $100 \mathrm{~cm}^{2}$ of stopper surface area) on $13 \mathrm{~mm}$ stoppers counted at $40 \mathrm{X} \&$ 100X magnifications.

References:

[1] < 788> Particulate Matter in Injections. In: The United States Pharmacopeia, $35^{\text {th }}$ revision. Rockville, MD: The United States Pharmacopeial Convention, (2012).

[2] Internal Standard ISO 8871-3: Elastomeric Parts for Parenterals and for Devices for Pharmaceutical Use — Part 3: Determination of Released-Particle Count, First Edition, 2003.

[3] Scott Aldrich is thanked for his many useful discussions and contributions to this work. 